\title{
Human macroecology: linking pattern and process in big-picture human ecology
}

\author{
William R. Burnside ${ }^{1 *}$, James H. Brown ${ }^{1,2}$, Oskar Burger ${ }^{3}$, Marcus J. Hamilton ${ }^{1,2,4}$, \\ Melanie Moses ${ }^{1,5}$, and Luis M.A. Bettencourt ${ }^{2,6}$ \\ ${ }^{1}$ Department of Biology, The University of New Mexico, MSC03 2020, 1 University of New Mexico, Albuquerque, NM 87131-0001, USA \\ ${ }^{2}$ Santa Fe Institute, 1399 Hyde Park Road, Santa Fe, NM 87501-8943, USA \\ ${ }^{3}$ Max Planck Institute for Demographic Research, Konrad-Zuse-Strasse 1, 18057 Rostock, Germany \\ ${ }^{4}$ Department of Anthropology, MSC01-1040, 1 University of New Mexico, Albuquerque, NM 87131, USA \\ ${ }^{5}$ Department of Computer Science, MSC01 1130, 1 University of New Mexico, Albuquerque, NM 87131, USA \\ ${ }^{6}$ Los Alamos National Laboratory, Theoretical Division, T-7, Mail Stop B284, Los Alamos, NM 87545, USA
}

\begin{abstract}
Humans have a dual nature. We are subject to the same natural laws and forces as other species yet dominate global ecology and exhibit enormous variation in energy use, cultural diversity, and apparent social organization. We suggest scientists tackle these challenges with a macroecological approach - using comparative statistical techniques to identify deep patterns of variation in large datasets and to test for causal mechanisms. We show the power of a metabolic perspective for interpreting these patterns and suggesting possible underlying mechanisms, one that focuses on the exchange of energy and materials within and among human societies and with the biophysical environment. Examples on human foraging ecology, life history, space use, population structure, disease ecology, cultural and linguistic diversity patterns, and industrial and urban systems showcase the power and promise of this approach.
\end{abstract}

Key words: macroecology, human, scale, metabolism, society, energy, diversity, network, industrial, hunter-gatherer.

\section{CONTENTS}

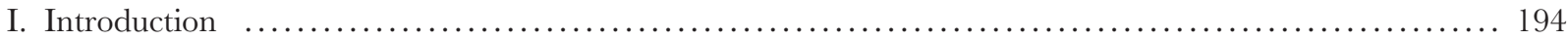

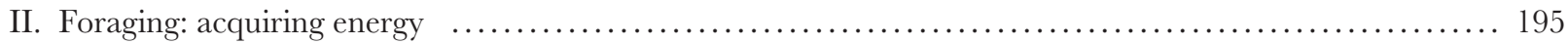

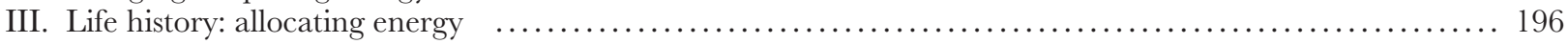

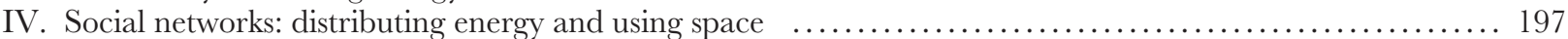

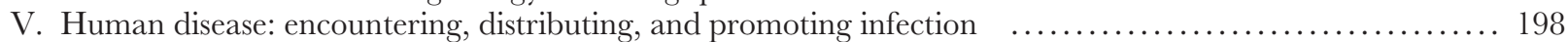

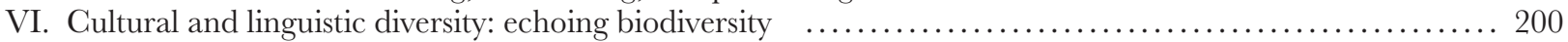

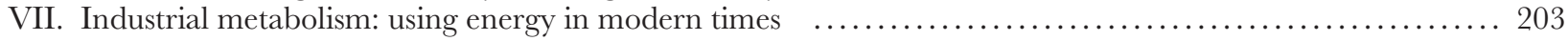

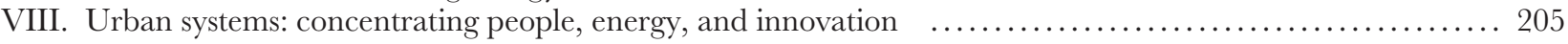

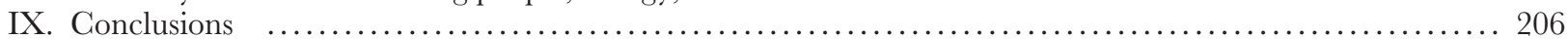

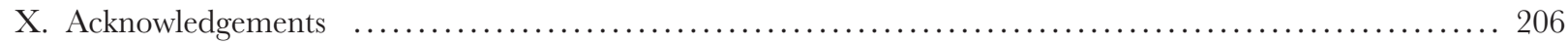

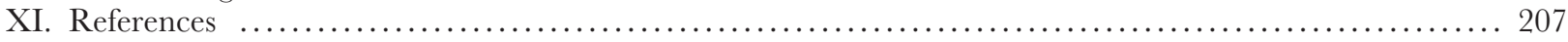

\section{INTRODUGTION}

Human ecology has an interesting duality. On the one hand, Homo sapiens is just another species, subject to the same physical, chemical, and biological laws as any animal, plant, or microbe. On the other hand, Homo sapiens is unique, the most powerful species ever to inhabit the Earth. Indeed, in just a few thousand years, this highly social mammal has spread out of Africa to colonize the globe and use technologies of hunting, fishing, agriculture, and industry to transform the ecosystems and biodiversity of the planet.

One might think that ecologists would study human ecology. Many ecologists do study impacts of humans on the environment, focusing on climate change, biodiversity loss,

* Address for correspondence (E-mail: burnsidewr@gmail.com, bburnsid@unm.edu; Tel: +1 505-908-4387). 
land use practices, pollution, and the destruction and fragmentation of habitats. Few ecologists, however, study the influence of the environment on humans, including the effects of biotic, abiotic, and social conditions on population growth, demography, health, resource use, and economy of our own species. Indeed, that focus is largely the preserve of the social sciences, especially anthropology, sociology, economics, geography, and public health.

Our premise is that human ecology is also a natural science, so it can be pursued using the same conceptual framework, analytical rigour, methodological approaches, and technological tools that ecologists apply to non-human systems. One challenge is that human ecology exhibits enormous variation over both time and space and across the spectrum of socio-economic development, from hunter-gatherers and pastoralists to horticulturalists, agriculturalists, and members of developed industrial societies. One answer to this challenge is to document patterns across scales and to evaluate underlying mechanistic hypotheses. In essence, we suggest adopting a macroecological approach - taking a large-scale, comparative, statistical perspective to identify important patterns of variation and test for causal mechanisms (e.g. Brown, 1995; Gaston \& Blackburn, 2000). We define human macroecology as the study of human-environment interactions across spatial and temporal scales, linking small-scale interactions with large-scale, emergent patterns and their underlying processes.

In the following sections, we present selected examples to highlight some of the unique perspectives, new questions, and recent empirical and theoretical advances in human macroecology. We characterize dimensions and consequences of the human niche: interactions with the environment that affect the abundance, distribution, diversity, and social, economic, and technological development of human populations. We adopt a metabolic perspective that focuses on the exchange of energy and materials between humans and their environments and the flows, pools, and transformations of these resources into, out of, within, and among societies. We cover a wide spectrum, from how minimally acculturated hunter-gathers form social groups to forage for food, exchange information, and use space, to how modern technological societies use extra-metabolic energy, especially fossil fuels, and resource supply networks to support dense populations in large cities.

\section{FORAGING: ACQUIRING ENERGY}

Like other animals, humans require energy and nutrients from food to support their metabolism. Patterns and processes of food acquisition in minimally acculturated humans highlight fundamental features of the human niche. Hunting and gathering was the socio-economic framework for the vast majority of human history. The study of traditional non-industrial societies offers valuable insights into human evolution and ecology, and large-scale, cross-cultural studies of variation among hunter-gatherer cultures have a venerable

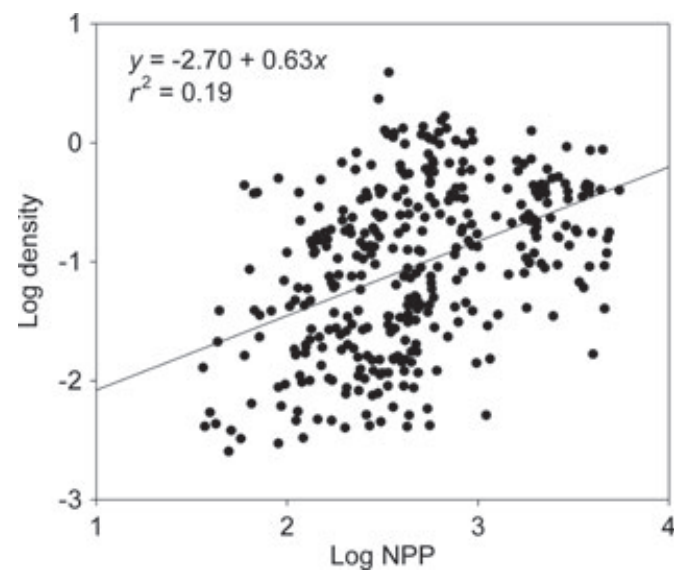

Fig. 1. Population density of traditional foraging societies versus net primary productivity (NPP) of the local environment. The relationship is significant $(P<0.005)$, although there is much unexplained variation, likely due to variables such as the proportion of plant and animal foods in the diet and the relative use of terrestrial, fresh-water, and marine resources. Data are from Binford (2001).

history in anthropology (e.g. Steward, 1938; Murdoch, 1967; Tindale, 1974; Kelly, 1995; Binford, 2001). Despite extremely diverse diets and foraging behaviours, traditional humans search for food in broadly consistent ways. Like other social animals, such as crows, wolves, lions, and dolphins, humans usually forage in groups (Winterhalder \& Smith, 2000). Foraging groups in productive environments travel shorter distances and have smaller home ranges and higher population densities than societies in less-productive cold or arid environments (Fig. 1) (Kelly, 1995; Binford, 2001).

Hunter-gatherers are also subject to constraints of trophic position and attendant energy supply. Groups that rely more on hunting animal prey and less on gathering plant foods tend to have lower population densities, occupy larger areas, and move more frequently and over greater distances (Kelly, 1995). Not surprisingly, population densities tend to be high in productive areas, such as river valleys and flood plains, and low in unproductive high-latitude, high-elevation, and desert areas. Population densities also tend to be high along productive coasts and large rivers where humans exploit nutrient-rich aquatic resources, such as fish and shellfish (Kelly, 1995; Binford, 2001). These macroscopic foraging patterns are consistent with humans being optimal foragers who exploit diverse and patchy resources in proportion to their energetic profitability (Sutherland, 1996).

Despite these similarities to other animals, human foragers are distinctive in three ways. First, humans have an exceptionally wide diet breadth. For example, in addition to using many plants Ache hunter-gatherers in the Amazon Basin of Paraguay harvest at least 263 species of game, including birds, mammals, reptiles, and fish (Kaplan et al., 2000). Second, despite their dietary diversity humans preferentially forage for food resources that are highly profitable but rare and hard to acquire, such as large game. Ache hunters and Aleut whalers typically go for days with little or no success. The 
potential disadvantages of specializing on large, rare prey are offset by hunting in cooperative groups and sharing the returns, thereby reducing risk and per capita variance in success (Winterhalder, 1996). Across a worldwide ethnographic sample, large, unpredictable food items are more likely to be shared than small, predictable ones (Gurven, 2004). Although some other primates also share food, the ubiquity of food sharing among distantly related individuals is uniquely human (Kaplan et al., 2000). So humans tend to be optimal social foragers, concentrating on food resources that provide maximal returns per unit effort and using cooperative foraging and food sharing to increase the rate and decrease the variance in energy intake. By efficiently targeting large game, prehistoric humans contributed to size-selective extinctions of megafauna on multiple continents (Lyons, Smith \& Brown, 2004) while contemporary humans have hunted whales to near extinction and skewed body-size distributions of commercial fish stocks (Jennings \& Reynolds, 2007). Third, humans occupy a high-skill foraging niche, using methods that may take years to master and harvesting a range of foods that require sophisticated understanding of local natural history, harvesting technologies, and intensive processing techniques (Kaplan \& Robson, 2002). Developing these foraging skills requires long-term learning in social groups.

These attributes of the human foraging niche have several implications for human evolutionary ecology. Wide diet breadth, cooperative hunting, food sharing, and food processing allowed groups to maintain relatively dense and stable populations. The need to learn the natural history of plants and animals used for food, fiber, and medicine and the technologies used to harvest and prepare them selected for a general intelligence that emphasized memory and spatial relations as well as communication, cooperation, and planning (Kaplan \& Robson, 2002). The benefits of distributing shared food resources favoured the formation of social networks and selected for behaviours based on reciprocity and kinship. As prehistoric populations acquired these uniquely human traits, they spread rapidly out of their ancestral home in tropical Africa, exploiting new food resources and colonizing new environments.

\section{LIFE HISTORY: ALLOGATING ENERGY}

The energy acquired by foraging humans is processed through metabolism and allocated to fuel growth, reproduction, and maintenance. The balancing of income and expenditure determines the energy budget. The income comes from foraging, and the expenditure determines the life history. A life history is the pattern, over an organism's life, for timing key events and allocating resources to maintenance, growth, and reproduction. It is an evolved answer to questions such as how fast to grow, when to reproduce, how long to live, how many offspring to have, and how much resources to invest in each one (Charnov, 1991; Roff, 2002). Life histories have evolved by natural selection to maximize fitness, constrained by trade-offs imposed by the finite energy budget. So, for example, energy invested in maintenance cannot be allocated to growing or producing offspring, and energy invested in reproduction can be used to produce either a few large offspring or many small offspring. Comparing human life-history traits to those of other species illuminates how humans simultaneously obey the same laws as other organisms and where humans use technology, sociality, and culture to lift some constraints in novel ways.

Humans fit the general pattern of having a relatively slow life history as a relatively large animal. Within major animal groups, such as mammals, larger species tend to "live slower lives" (Purvis et al., 2003). Growth rates, lifespans, and other life-history variables increase more slowly than body size due to size-related constraints on metabolism, which fuels the life history. Metabolic rates rise sublinearly with body size because the larger vascular systems of larger animals take longer to service their body's cells, which can metabolize sugars only as fast as they receive them (West, Brown \& Enquist, 1997). Since the life history is allocated from the metabolic energy budget, humans and other large animals have slow life histories (e.g. Peters, 1983). However, individual taxa often deviate from the general relationship, as shown in Fig. 2, due to selection for specific traits.

Compared to other mammals, the human life history is exceptionally slow, characterized by slow growth, a long time to maturity and lifespan, and a low rate of reproduction. For

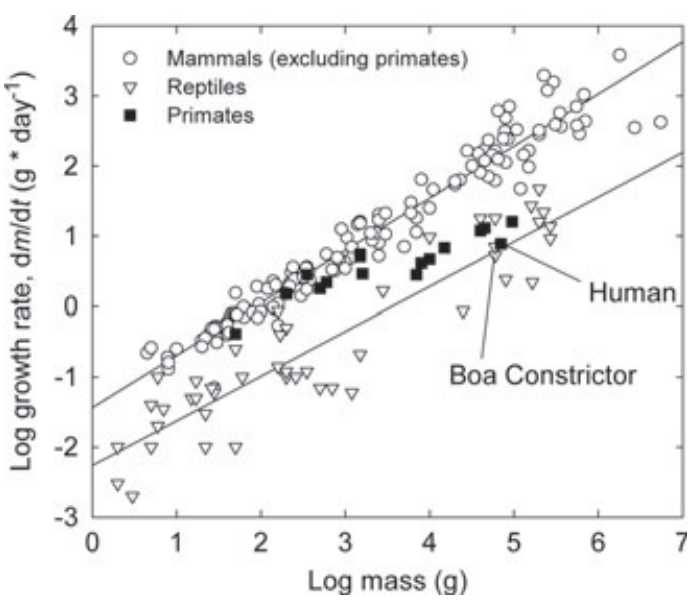

Fig. 2. Growth rate as a function of body mass for species of mammals and reptiles plotted on logarithmic axes [from Case (1978) and Walker et al. (2006)]. The regression lines for mammals and reptiles give the scaling of growth rate with body size: $\log (\mathrm{dm} / \mathrm{dt})=\log (\mathrm{a})+\delta \log (\mathrm{m})$, where $\mathrm{m}$ is the mass in $\mathrm{g}$, $\mathrm{dm} / \mathrm{dt}$ is the change in mass per unit time, $\log (\mathrm{a})$ is the $\mathrm{y}$-axis intercept, and $\delta$ is the slope of the line, or scaling exponent. The near-parallel lines indicate that growth rates of reptiles are generally slower than those of mammals but scale similarly with size. Small-bodied primates have growth rates similar to those of other mammals, but larger primates have diverged toward progressively lower growth rates. Growth rates of humans are even lower than those of other primates and similar to those of reptiles of comparable size. Other human life-history traits, such as a long time to reproduction and a long lifespan, also reflect our exceptionally slow life histories. 
example, human growth rate is more similar to that of a large reptile than to that of a typical mammal (Fig. 2; Walker et al., 2006). The human life history reflects an evolutionary trend in primates towards slower growth rates and correspondingly lower mortality rates and longer lifespans with increasing body size (Charnov \& Berrigan, 1993). Indeed, even in poor environments human hunter-gatherers have higher survival at all ages than chimpanzees, our closest relative (Hill et al., 2001). Humans are also unique in having a lifespan substantially longer than the reproductive period, so that post-reproductive females comprise a substantial fraction of hunter-gather as well as modern industrial populations (Hawkes \& Paine, 2006). This life history is consistent with suggestions that selection on primates and especially on humans has placed a premium on large brain size and accompanying learning and cognitive capacities, with consequent slow growth rates, long development times, and low mortality (Charnov \& Berrigan, 1993; Walker et al., 2006).

The unique pattern of survival well beyond the reproductive period is linked to our slow life history through sociality (Kaplan et al., 2000). Among hunter-gatherers, the metabolic demand of multiple dependents exceeds the foraging capacity of a single individual. Cooperative foraging and food sharing supply the essential 'extra-maternal' resources (Kaplan et al., 2000; Hrdy, 2006). Adult males hunt in social groups, harvest more resources than they can consume, and bring food back, which is distributed to other group members - females, young, and old - through a complex exchange network. Females typically gather plant foods, and non-reproductive females, including grandmothers and older children, contribute to foraging, food processing, and child care. These contributions of males and non-reproductive females enhance the reproductive success of breeding females, increasing fecundity by shortening the time to weaning and increasing the survivorship of offspring (Marlowe, 2001). Foraging productivity of non-breeding individuals, sharing of food, and social care of young are the crux of the uniquely human life history, with a long period of juvenile dependence, high offspring survival rate, and multiple dependent offspring (Kaplan et al., 2000; Gurven \& Walker, 2006; Hrdy, 2006).

\section{SOGIAL NETWORKS: DISTRIBUTING ENERGY AND USING SPACE}

A key to understanding the unique features of human life history is to elucidate how social networks affect the rates and directions of resource flows among individuals and especially to offspring. Where do humans acquire these resources, how do they distribute them, and how do patterns of distribution affect and reflect human ecology?

Humans harvest energetic and material resources that sustain them from the ecosystems in which they are embedded. The social organizations of nonindustrial societies are shaped by several forces. In part, they reflect the intrinsic Darwinian imperative to allocate resources to different components of the life history and to individuals of different ages and degrees of relatedness so as to maximize reproductive success. In part, they reflect extrinsic environmental constraints on resource availability.

Resource constraints are especially evident for huntergatherers, who obtain nearly all of their energy and materials for fuel, clothing, food, shelter, and non-lithic tools from plants and animals. Hunter-gatherer cultures must contend with temporal and spatial variation in the abundance and distribution of these biological resources. Macroecological perspectives have been applied to explore variation in the abundance, distribution, and diversity of hunter-gatherer cultures based on theoretical concepts of networks, allometric scaling, and metabolic ecology (Hamilton et al., 2007a, b, 2009). Indeed, remarkable symmetries in space use and social organization across hunter-gatherer societies worldwide suggest that different foraging cultures have experienced and adapted to resource constraints in fundamentally similar ways.

A fundamental concept in mammalian ecology is the home range, the area of space an individual uses on a regular basis to acquire the resources for growth, maintenance, and reproduction. The home range, $H$, can be defined as $H \equiv B / R$, where $B$ is the rate of resource use of an individual and $R$ is the rate of resource supply per unit area. The rate of resource use can be equated to the metabolic rate of a free-living ani$\mathrm{mal}$ in the field, so larger animals have higher field metabolic rates and, predictably, larger home ranges (McNab, 1963). Given the home range of an individual, $H$, and assuming this individual's space use is typical for its population, then the total territory area, $A$, required by a population of $\mathcal{N}$ individuals to meet their metabolic requirements is $A=H \mathcal{N}^{\beta}$. The exponent $\beta$ quantifies how the home range area scales with population size: when $\beta=1$ the group territory area is simply the sum of individual space requirements; when $\beta>1$ individual space requirements increase with population size; and when $\beta<1$ individual space requirements decrease with population size (Hamilton et al., 2007a). We can also derive other metrics of population size and space use and examine their dependencies on the scaling exponent, $\beta$. For example, population density is the number of individuals per unit area, or $\frac{\mathcal{N}}{A}=H^{-1} \mathcal{N}^{1-\beta}$. Thus, population density is simply the inverse of home range when $\beta=1$ but increases with population size when $\beta<1$ and decreases when $\beta>1$. Similarly, for a steady state (non-growing) population we can express the equilibrium abundance as $\mathcal{N}=K=\left(\frac{A}{H} \frac{1}{\beta}\right)$ and thereby define the carrying capacity, $K$, as the filling of an area, $A$, with a social group of $\mathcal{N}$ individuals given their home range requirements, $H$, and their spatial organization, $\beta$.

Applying this framework to humans and using a global sample of 339 hunter-gatherer societies shows how the scaling exponent, $\beta$, is directly related to the carrying capacity (Hamilton et al., 2009). The space required by an individual is not constant but instead decreases with increasing population size. As shown in Fig. 3A, $\beta<1$ and close to 3/4, suggesting an economy of scale (Hamilton et al., 2007a). Viewed from a slightly different perspective, the area of space used by an individual decreases with increasing population size at a 


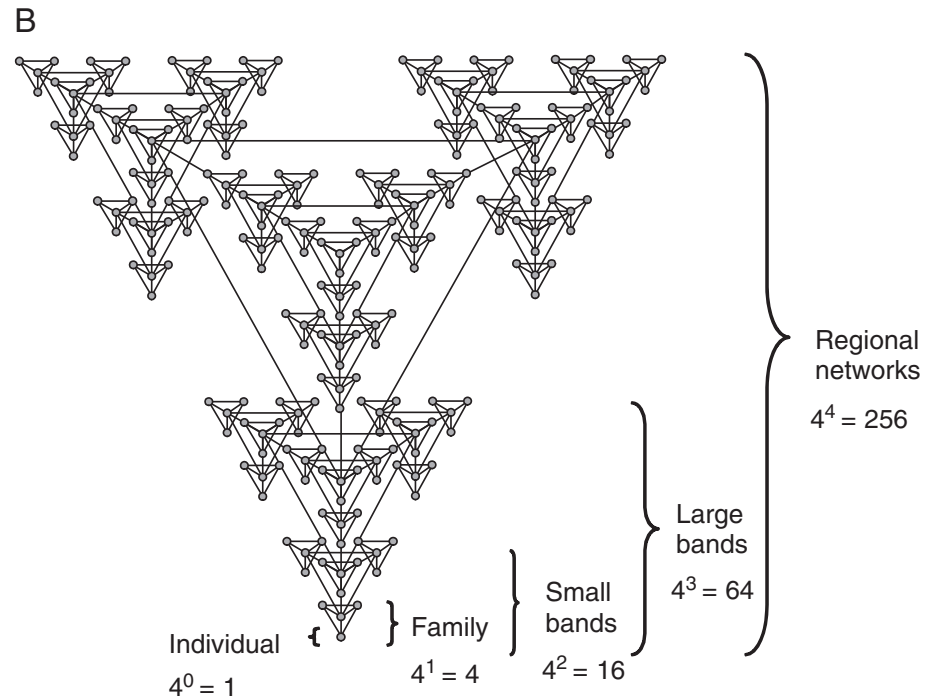

Fig. 3. (A) The total area, $A$, used by a hunter-gatherer population versus population size, $\mathcal{N}$. Although there is considerable unexplained variation $\left(r^{2}=0.24\right)$, the sublinear scaling $\left(A \sim \mathcal{N}^{0.7}\right)$ is indicated by the fact that the fitted slopes of the overall relationship (solid line; $\beta=0.70$ ) and the upper and lower bounds (dashed lines) are all significantly less than 1 (after Hamilton et al., 2007a). (B) A diagram depicting the self-similar topology of a hunter-gatherer social network, showing the typical factor of four separating the nested hierarchy of group sizes (after Hamilton et al., 2007b). We suggest that this topology maximizes the flux of resources through traditional human social networks, reducing the average area required per individual as population size increases.

rate of $A / \mathcal{N} \propto \mathcal{N}^{-1 / 4}$. However, because individual resource requirements are essentially constant - field metabolic rates do not change-the rate of resource use per unit area, $R$, increases with population size, as $R \propto \mathcal{N}^{1 / 4}$. Therefore, larger foraging societies are able to extract more resources per unit area of their territory, which implies that either exclusive home ranges are smaller or that overlap among shared home ranges increases. As a consequence of these economies of scale, carrying capacities of the largest human populations in this sample, social groups of a few thousand individuals, are about five times higher than expected if individual space requirements were fixed so that group territory size just scaled up linearly with population size. Effectively, large hunter-gather societies tend to use their environments more efficiently than small ones, extracting more resources per unit area.

From sedentary coastal fishing societies to nomadic desert bands, hunter-gatherer cultures worldwide also show remarkable similarities in social organization despite large differences in food base and habitat (Hamilton et al., $2007 b$ ). Societies are organized into a nested hierarchy of modular group sizes, from individual nuclear family units, to seasonal residential groups, up to self-recognized regional populations of about 1000 individuals. Moreover, the nesting of subgroups within higher order groups is statistically selfsimilar: group size increases by a factor of approximately four with each increasing level of the hierarchy. We hypothesize that this pattern reflects a scaling up from the nuclear family as the fundamental unit of social organization, and in a non-growing population the average family size is four, two parents and two offspring (Fig. 3B). The hierarchical organization of these social networks is remarkably similar to those of other social mammal species: gelada baboons (Theropithecus gelada), hamadryas baboons (Papio hamadryas), African elephants (Loxodonta africana), and orcas (Orcinus orca) all have scaling ratios between three and four (Hill, Bentley \& Dunbar, 2008).

Such symmetries across cultures that vary widely in their environmental circumstances suggest universal processes underlying how politically egalitarian hunter-gatherer cultures self-organize (Hamilton et al., 2007b). We posit that the consistently fractal-like structure of traditional human societies serves to maximize the flux of energy, materials, and information through social networks. Similar physical constraints and optimization principles underlie the fractallike networks of animal societies, plant architectures, stream networks, and mammalian vascular systems (Brown et al., 2002; Hill et al., 2008).

\section{HUMAN DISEASE: ENGOUNTERING, DISTRIBUTING, AND PROMOTING INFECTION}

As societies grow, their ramifying social networks distribute more than energy, materials, and information. Parasites and pathogens move among people, and increased contact among individuals in denser populations with larger social networks spread these scourges further and faster.

"Disease ecology" is a vibrant and important field with a large and rapidly growing literature (e.g. Jones et al., 2008; Smith et al., 2007; Guernier, Hochberg \& Guégan, 2004). Many studies examine spatial and temporal dynamics of specific diseases and macroparasites in an ecological context 
(e.g. Grenfell \& Bolker, 1998). Others are primarily theoretical and adapt mathematical models from epidemiology and ecology to address the origin, spread, and dynamics of diseases (e.g. Anderson \& May, 1991). Here we take a macroecological approach to human disease and highlight where such a perspective might be especially informative. We focus on the ecology of humans as hosts, the ecology of human parasites and pathogens, and the implications of global change.

As hosts, humans display three important macroscopic patterns: (i) as humans spread geographically, they take along some parasites and pathogens; (ii) as humans colonize new areas, they encounter new organisms, including new pathogens, new parasites, and new alternative hosts for existing pathogens and parasites; and (iii) as agriculture and industrialization have increased human population density and frequency of contact they have drastically affected the ecology of disease. Within the last 50,000 years, anatomically modern humans have migrated out of Africa and spread across Eurasia, Australia, and the Americas. As humans colonized temperate latitudes, they left behind many tropical diseases but brought along others, such as cholera (Lafferty, 2009). More recently, migrating Eurasian populations spread their diseases to previously unexposed populations, causing devastating epidemics. As population density increased with increasing agriculture and urbanization, the number and frequency of diseases increased as new emerging pathogens switched from wild and domesticated animals to humans and as vectors such as mosquitoes and fleas transmitted pathogens between denser and more- frequently infected hosts (Wolfe, Dunavan \& Diamond, 2007; Barrett et al., 1998).

Relatively recent changes in human macroecology affect our role as hosts. As long-distance travel and trade networks have expanded, parasites and pathogens have crossed previously impermeable biogeographic barriers. Rising population densities have fostered the geographic spread of 'crowd-epidemic diseases' such as influenza and SARS (Wolfe et al., 2007). In just the last thirty years, increased contact with wild, commensal, and domesticated animals due to ecological and social changes has increased the temporal frequency and spatial scale of outbreaks of 'zoonotic diseases' (Wilcox \& Gubler, 2005). Although advances in nutrition, public health, and medicine have generally extended average lifespans, the coevolutionary race between contemporary humans and our enemies continues unabated and is a major public health concern (Barrett et al., 1998; McMichael, 2004).

Human parasites and pathogens also display macroecological patterns, which offer novel insights into disease ecology. First, there is a latitudinal gradient in the diversity of human disease organisms, similar to the diversity gradients in animals, plants, and microbes. As shown in Fig. 4, there are more diseases in the tropics than at higher latitudes (Guernier et al., 2004). Interestingly, in other primates only vector-borne parasites, and not viral diseases and helminth parasites, are most diverse in the tropics (Nunn et al., 2005). Additionally, as illustrated in Fig. 4B, assemblages of pathogens form nested subsets, so that humans living at progressively higher latitudes tend to be infected with only a subset of the parasites and diseases in the tropics (Guernier et al., 2004).

A second pattern is that epidemics display 'hierarchies of infection' across gradients of population density, with infections occurring more frequently and outbreaks lasting longer in large cities (Grenfell \& Bolker, 1998). Models that represent human population structure as nested hierarchies of subpopulations (see above and Fig. 3B) and that incorporate realistic movements of individuals, including
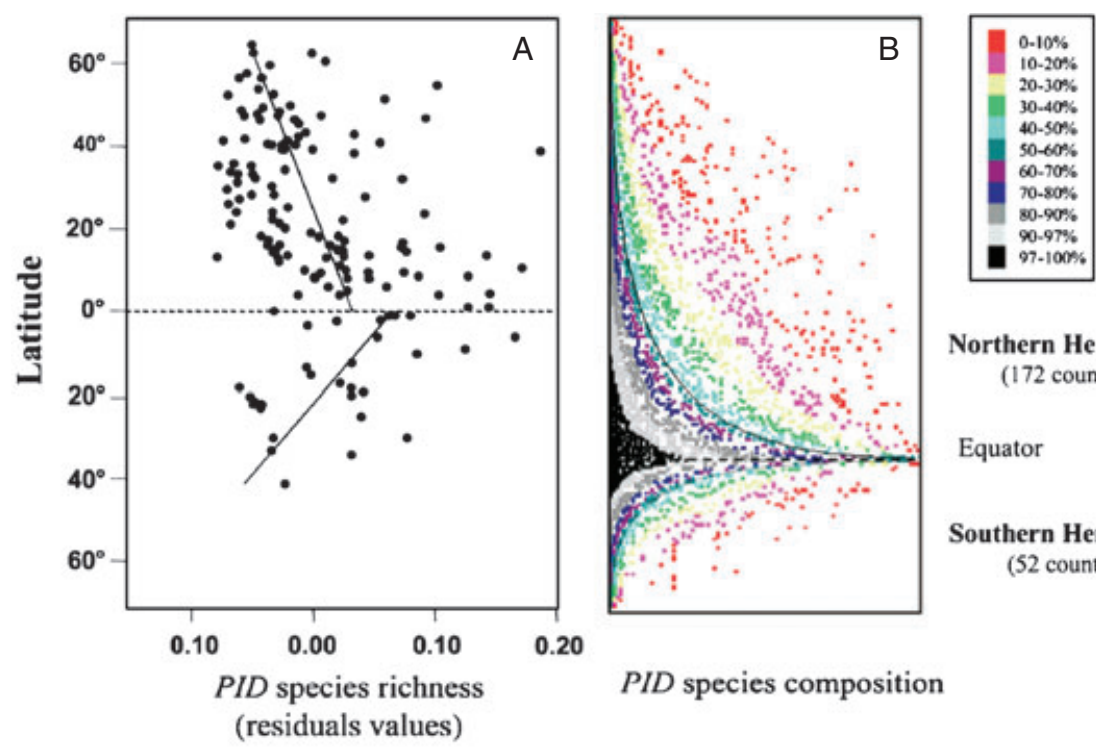

Northern Hemisphere

(172 countries)

Equator

Southern Hemisphere

( 52 countries)

Fig. 4. Human parasites and pathogens display macroecological patterns. (A) Species richness of human parasitic and infectious diseases (PIDs) is higher at tropical latitudes and higher in the northern hemisphere, with its greater land area, than in the southern hemisphere. B) In both hemispheres, the relatively few disease organisms present at higher latitudes are subsets and hence a smaller percentage of the larger number found at lower latitudes (after Guernier et al., 2004). 
both small-scale movements, such as to and from work, and large-scale movements, such as international travel, capture the spatial patterns and temporal dynamics of real epidemics (e.g. Watts et al., 2005; Viboud et al., 2006).

A third pattern is that geographic and temporal patterns of disease depend on host specificity. Many human-only diseases are globally distributed, because humans take these organisms with them as they travel around the world. By contrast, most zoonotic pathogens are regionally or even locally restricted because they depend on specific, geographically restricted reservoir hosts (Smith et al., 2007). New emerging infectious diseases are mostly zoonotic, and most of these do not become epidemic (Jones et al., 2008).

All three of these macroecological patterns of human disease - latitudinal gradients, nested hierarchies, and their joint dependence on host specificity — reflect basic ecological processes. The latitudinal gradient of pathogen diversity is strongly correlated with climatic variables, including both temperature and precipitation (Guernier et al., 2004). Warm, moist conditions are conducive to the survival and spread of diverse species of pathogens, parasites, vectors, and reservoir hosts, including birds and other mammals (see Dunn et al., 2010). Higher temperatures closer to the tropics probably speed up rates of parasite and pathogen transmission, infection, and evolution by increasing the movement and frequency of encounters, decreasing generation times, increasing mutation rates, and intensifying selection and coevolutionary arms races with hosts and competitors (see Rohde, 1992; Allen, Brown \& Gillooly, 2002; Jablonski, Roy \& Valentine, 2006). The nested patterns of decreasing pathogen diversity with increasing distance away from the equator likely reflect the filtering effects of increasingly stressful climates and decreasing biotic interactions on parasite, pathogen, vector, and reservoir host diversity. The differences in the geographic distributions and epidemic dynamics between human-only and zoonotic diseases (Fig. 5) undoubtedly reflect differences in the abundance and distribution of Homo sapiens compared to the animal species that are sources of and reservoirs for diseases. Although $H$. sapiens has a population of about 7 billion and a truly cosmopolitan distribution, most of the animals that harbour zoonotics are rare or geographically restricted.

A macroecological perspective can also contribute to understanding effects of global change on human disease. By focusing on large-scale empirical patterns of abundance and distribution and seeking mechanistic theoretical explanations, macroecology complements 'the frequently local focus of global change biology' (Kerr, Kharouba \& Currie, 2007, p. 1581). For example, a macroecological approach and metabolic perspective helps to account for observed impacts of climate change on emerging patterns of disease. WHO estimates that 6-7\% of the incidence of malaria in some regions is due to recent climate change (McMichael, 2004). Other human parasites, pathogens, and vectors will undoubtedly shift their ranges with rising temperatures and changing precipitation patterns. One feature of human-caused change is biotic homogenization

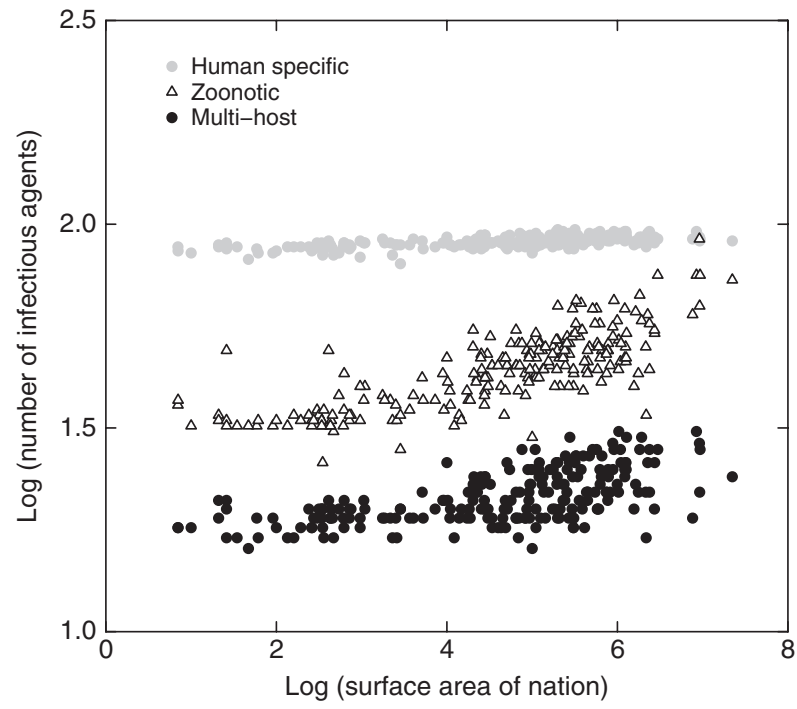

Fig. 5. A plot, on logarithmic axes, of number of infectious agents as a function of country area for three host categories: human-only, zoonotic (resident in native animals with occasional outbreaks in humans), and multi-host (life history includes a stage that infects a non-human host). The invariant human-specific pattern implies that diseases with direct human-to-human transmission are cosmopolitan, whereas the positive speciesarea relationships in the other categories show that agents that depend on non-human hosts are more restricted geographically (after Smith et al., 2007).

due to human-aided spread of invasive species (Kerr et al., 2007). We can expect that diseases, too, will become more homogenized and cosmopolitan as parasites, pathogens, and vectors expand their ranges. Macroecological perspectives that address such problems of variation and scale by drawing on comparisons across multiple pathogens and over geographic space and long periods of time should help us tackle these and other pressing questions of human disease ecology (Pascual \& Bouma, 2009). For example, Guernier \& Guégan (2009) found that most human parasites and pathogens conform to 'Rapoport's rule', a tendency for the geographic range sizes of species living further from the equator to be larger than the ranges of species in the tropics. If temperate parasites and pathogens have larger ranges in part because they are adapted to wider climatic ranges and so can live in more places, the expansion of tropical climates with global warming may select for smaller ranges and thus higher disease diversity further from the equator.

\section{GULTURAL AND LINGUISTIC DIVERSITY: EGHOING BIODIVERSITY}

One of the most striking features of human ecology is the similarity among the geographic patterns of diversity of indigenous human cultures and the diversity patterns of plant, animal, and microbe species. Recent studies have documented a latitudinal gradient in the diversity of aboriginal 
cultures and languages (e.g. Mace \& Pagel, 1995; Nettle, 1998; Cashdan, 2001; Collard \& Foley, 2002; Moore et al., 2002; see also Maffi, 2005). The geographic pattern mirrors species diversity of animals, plants, parasites, and pathogens, being highest in topographically diverse regions in the tropics, such as New Guinea, southern Asia, equatorial Africa, and Mesoamerica, and lowest in polar and desert regions (Fig. 6). In addition to these global and continental-scale patterns, there is substantial variation at regional to local scales. This reflects the influence of cultural history, sociopolitical factors, and local environments on cultural diversification, similar to the influences of phylogenetic history and taxon-specific niche relationships on biological diversification.

Three features of the macroscopic patterns are particularly interesting. First, human cultures generally occupy nonoverlapping ranges (Nettle, 1998), so the pattern is expressed in terms of density of cultures or sizes of tribal territories rather than as number of locally coexisting taxa, as for animal and plant species. Second, the patterns have been established rapidly - since modern humans expanded out of Africa about 50,000 years ago, and since they colonized the New World about 15,000 years ago (Collard \& Foley, 2002). Indeed, the time since settlement "has surprisingly little effect on language diversity" (Sutherland, 2003). Patterns of cultural and linguistic diversity are also strikingly similar to patterns of human-dispersed exotic plant and animal diversity, many of which were established within just the last few centuries (Sax, 2001). Third, as would be expected from the similar geographic patterns, cultural diversity and species diversity are correlated with similar environmental variables: both are high in regions with high temperature, rainfall, topographic relief, and habitat diversity [e.g. for cultural diversity see Nettle (1998) and Cashdan (2001); for species diversity see Hawkins et al. (2003)].

Are the similar patterns of cultural diversity and biodiversity generated by similar mechanistic processes? Two points seem particularly relevant. First, both cultural diversification and biological diversification are the result of a balance between coalescent processes that tend to keep a population together and disruptive processes that tend to break apart and isolate populations. Second, the same environmental variables operating in similar ways are likely to determine the balance between cohesive and divisive forces for both cultures and species. The rapid establishment and repeated, independent formation of similar latitudinal diversity gradients of

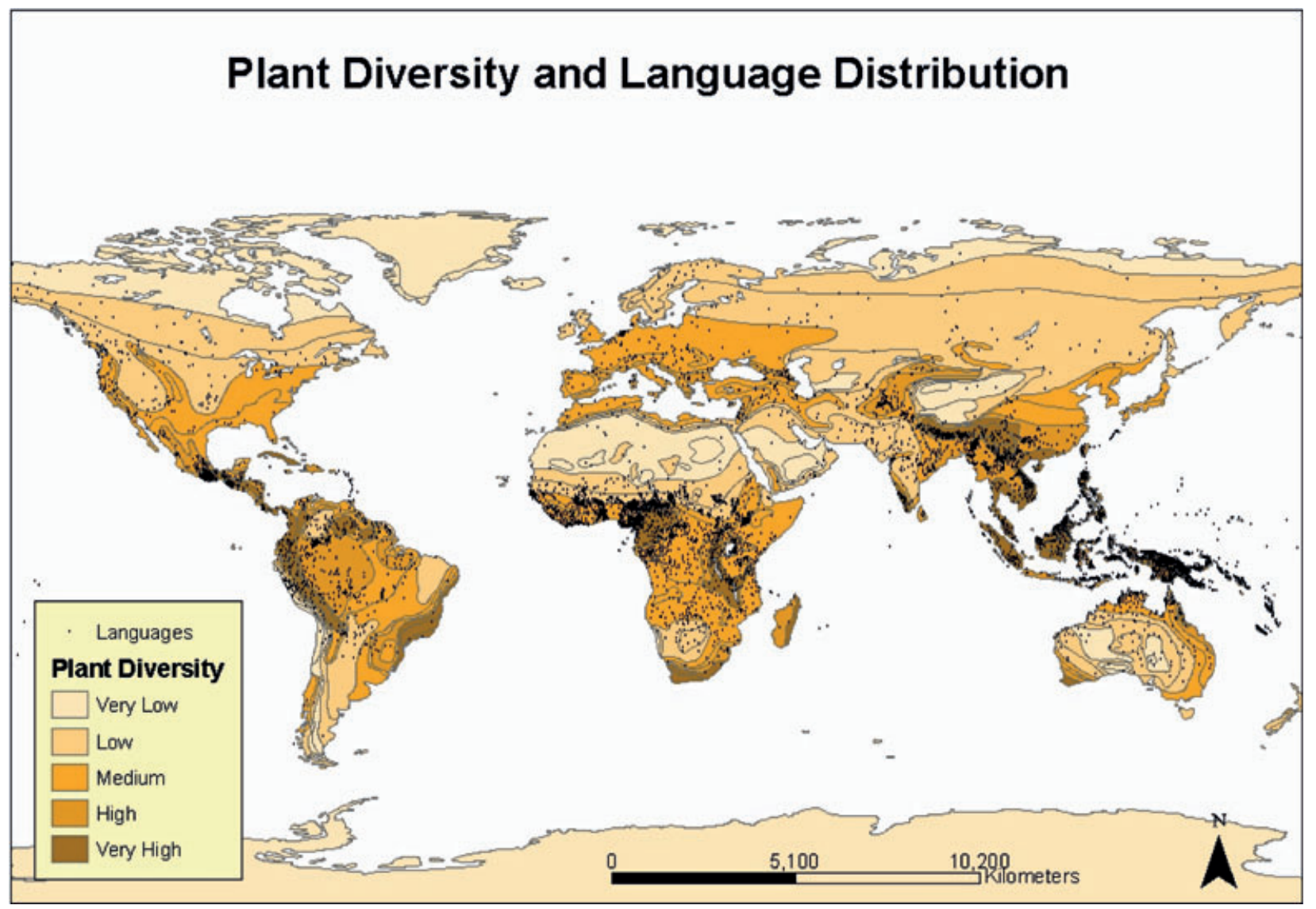

Fig. 6. Human linguistic diversity compared with the diversity of vascular plant species at a global scale. Darker shades correspond to higher levels of plant species richness; each dot indicates the centre of a living language. Both human languages and plant species are most diverse in mountainous areas of the tropics [after Stepp et al. (2004), based on data from Barthlott, Lauer \& Placke (1996), and Grimes (2000)]. 
human cultures and biological species on multiple continents suggest that the primary causes are ecological.

Three classes of ecological mechanisms may strongly affect these gradients: (1) environmental heterogeneity, due to temporal variation in weather and climate and spatial variation in topography, geology, and soil; (2) biotic productivity, due to spatial variation in rates of energy, water, and nutrient supply, and (3) Red Queen kinetics, due to spatial variation in temperature, which affects rates of metabolism, ecological interactions, evolution, and coevolution with other organisms. Red Queen kinetics refers to species interactions and attendant evolutionary arms races, which tend to increase with temperature through its effect on metabolism and in which species must evolve to persist, much like Alice in Through the Looking Glass must run just to stay in place in the Red Queen's race (Brown et al., 2004).

Empirical evidence and theory suggest that all three mechanisms, which are not mutually exclusive, may contribute to the similar patterns among cultures and species. Both cultural and biological diversity are highest in regions of high environmental heterogeneity, especially in mountainous regions of the tropics and semitropics (Cashdan, 2001; Stepp, Castaneda \& Cervone, 2005). At least two processes may contribute to this pattern. First, the occurrence of dramatically different environments in close proximity promotes differentiation based on specialization. For both cultures and species, spatial heterogeneity in abiotic conditions, habitat types, and ecological communities leads to the origin and cohesion of specialized local populations better able to tolerate the physiological stress, use the resources, and avoid the predators, parasites, and diseases in the distinctive local environments. Second, topographic relief and complex landscapes tend to create isolated and patchy environments, which have divisive effects, creating barriers, reducing migration, and promoting development of specialized populations.

Both cultural and biological diversity also tend to be high in regions of high net primary productivity, so where rates of supply of resources are high and relatively constant (Nettle, 1998; Hawkins et al., 2003; Field et al., 2008). All things being equal, more-productive environments can support more individuals per unit area. Assuming some minimum viable population size required to avoid extinction due to demographic and environmental stochasticity, more individuals can aggregate into more populations with smaller ranges, promoting greater biological and cultural diversity (Moore et al., 2002). For humans, more-productive areas also tend to have longer growing seasons, reducing variation in food supplies across the seasons and facilitating the formation of small, sedentary, specialized cultural and linguistic groups (Nettle, 1998; Smith, 2001). Intriguingly, human languages display a Rapoport's rule of increasing 'range size' with increasing distance from the equator (Mace \& Pagel, 1995), much like human parasites and pathogens.

Finally, cultural diversity tends to increase exponentially with environmental temperature, just like species diversity (Fig. 7). This pattern is consistent with the fact that metabolic rates increase exponentially with temperature. In warmer climates, higher metabolic rates in plants and ectothermic animals, including parasites, pathogens, and invertebrate vectors, increase rates of ecological interactions and evolutionary processes, and these in turn generate and maintain higher diversity (Rohde, 1992; Brown et al., 2004; Allen et al., 2002). Indeed, phylogenetic evidence suggests higher rates of diversification among tropical clades and palaeontological findings support the existence of higher rates of origination among tropical taxa (Mittelbach et al., 2007). Higher plant, animal, and microbial species richness and diversification rates may affect cultural and linguistic diversity in several ways. Traditional human societies have specialized vocabularies for local plants, animals, parasites, and diseases; specialized technologies and customs for food capture and processing; and specialized plant and fungal pharmacopeias. (Berlin, 1992). In addition, temperaturedependent Red Queen processes are consistent with the high incidences of parasites and diseases in tropical human, animal, and plant populations (see above and Grenfell \& Dobson, 1995; Guernier et al., 2004). Limiting movements and interactions with neighbouring groups should reduce the risk of catching and spreading diseases, promoting cultural and linguistic diversification (Fincher \& Thornhill, 2008). Supporting this possibility, there is a positive correlation between pathogen prevalence and the degree of collectivistic
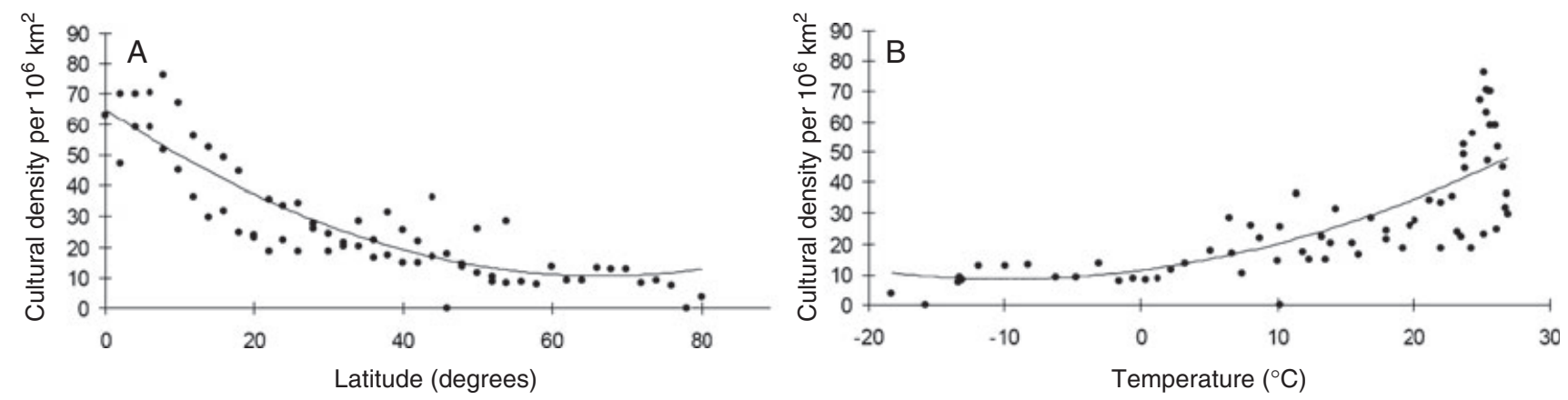

Fig. 7. Latitudinal (A) and temperature (B) gradients of human cultural diversity. There is an exponential relationship between the density of cultures and environmental temperature. The exponential form of this relationship appears to be a diagnostic signal of the exponential effect of temperature on metabolic rate and consequently on "Red Queen" processes of ecological interactions and coevolutionary rates (after Collard \& Foley, 2002, with one outlier removed representing tropical islands). 
and ethnocentric values (Fincher et al., 2008) as well as a positive correlation between infectious disease diversity and the incidence of intrastate armed conflict and civil war (Letendre, Fincher \& Thornhill, 2010). Broadly put, the Red Queen argument suggests that as biodiversity increases with rising temperature, there is a corresponding increase in interactions between humans and other organisms, which contributes to the diversification of cultures and languages.

\section{INDUSTRIAL METABOLISM: USING ENERGY IN MODERN TIMES}

Humans evolved as hunter-gatherers, and we have seen how this ancestral context shaped macroecological patterns of cultural diversity, infectious disease, population structure, space use, life history, and foraging ecology. In just the last 10,000 years, however, the agricultural, industrial, and high-tech revolutions have introduced new socioeconomic constraints and altered old ones. These revolutions were possible because humans learned to harness non-metabolic energy, first wood and dung and now primarily fossil fuels. Human biological metabolism is about $120 \mathrm{~W}$, comparable to that of other mammals of our size. But contemporary humans use much more energy, from about $300 \mathrm{~W}$ in huntergatherer societies to $11,000 \mathrm{~W}$ in the most developed nations (Moses \& Brown, 2003; World Resources Institute, 2009). Among hunter-gatherers, this energy comes from burning biofuels such as wood and dung. Agricultural societies burn biofuels and use animal labour. The enormous non-biological metabolism of contemporary industrial societies is fueled by oil, coal, and natural gas and by nuclear, solar and hydroelectric power. The average U.S. citizen uses about 100 times more energy than his or her biological metabolism.

Does the extra-metabolic energy use affect life history? Among animals, including aboriginal humans, metabolic rate constrains the life history because all biological activity is fueled by metabolism (Brown et al., 2004). In modern societies, however, female fecundity and reproductive rates are not constrained by biological metabolism but instead vary with total energy use (Moses \& Brown, 2003). Human reproductive rates are negatively correlated with per capita energy use across modern nations (Fig. 8). Fossil fuels, by supplying extra-metabolic energy, extend the negative relationship between reproductive rate and mass-specific metabolic rate seen in other mammals, including other primates. Put quantitatively, metabolic rate, $B$, scales with body mass, $M$, as $B \propto M^{3 / 4}$, and fertility rate, $F$, as $F \propto M^{-1 / 4}$. Rearranging terms gives fertility scaling with per capita energy use as $F \propto B^{-1 / 3}$, the scaling relation seen for mammals in Fig. 8.

Humans and other primates have slower life histories and lower fecundities than other mammals. The relationship between fertility rate and rate of per capita energy use across modern nations appears simply to extend the relationship between reproductive rate and metabolic rate in primates. As explained in Section III, metabolic rate fuels allocation to

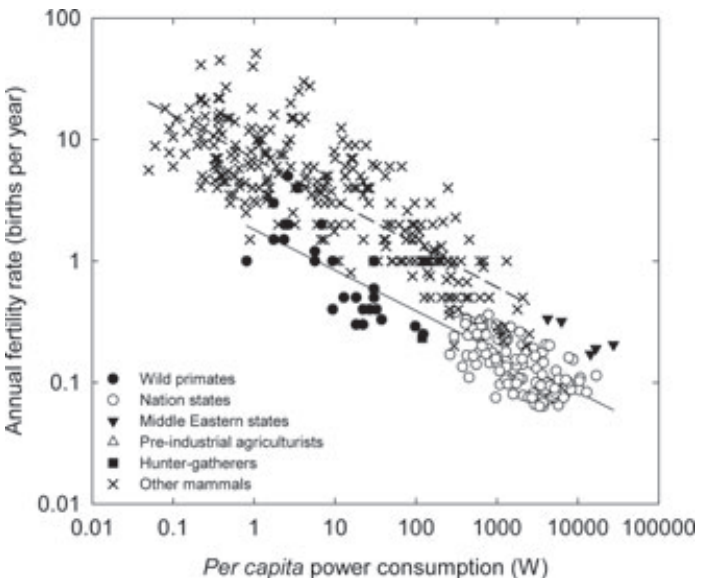

Fig. 8. Fertility rate, measured as number of offspring per year versus energy use $(\mathrm{W})$ in mammals. This plot, on logarithmic axes, includes data for non-primate mammals (crosses) and primates (black circles) as a function of metabolic rate as well as for modern humans as a function of energy consumed from all sources. The human data span the entire spectrum of development, from hunter-gatherers (squares) to members of the most energy-intensive nation-states (black triangles). The slope of the parallel lines, $-1 / 3$, corresponds to the theoretically predicted relationship. Note that the human pattern across nations continues the scaling relationship seen in primates (solid line) (after Moses \& Brown, 2003; data from World Resources Institute, 2009).

life history, leading to a predictable scaling with body size: larger organisms have slower life histories. The use of extrametabolic energy by modern societies effectively increases per capita metabolic rate, and the non-linear scaling relationship of fecundity with energy use, $F \propto B^{-1 / 3}$, has led to reduced fecundity. Indeed, the total energy use from fossil fuels and other sources for a female in the U.S. today is equivalent to the metabolic rate predicted for a hypothetical $30,000 \mathrm{~kg}$ primate, and the average U.S. female's lifetime fertility rate is similar to what would be predicted for a primate this size. The qualitative relationship between fecundity and economic development is well known to social scientists as part of the 'demographic transition'. The metabolic perspective of macroecology provides a quantitative explanation for the drop in fertility with economic development based on lifehistory theory.

Given that members of wealthier and more energyintensive societies can presumably support more children, why does human fertility drop with societal energy use? As explained above, metabolism constrains the life history by determining the energy available for offspring to grow to maturity. How much energy is required to raise a fit, competitive child in a modern industrial society? It takes far more than the $120 \mathrm{~W}$ of biological metabolism because of the extra-metabolic energy used to grow and transport food in distant locations; to build, heat, and cool the home; to drive to school and music lessons; to provide health care and formal education; and to supply ever more electronics and other consumer goods. In the U.S. middle class, this amounts to 
about $\$ 220,000$ and the equivalent number of barrels of oil to raise a child to age 17 (Lino, 2010). The more energy required to raise a child, the fewer children women tend to have.

Given the analogy of industrial metabolism with biological metabolism, consider how a contemporary society is like a whole organism. Both require energy and resources, which are delivered through networks. Biological metabolism is fueled by energy-rich sugars and micronutrients delivered by vascular networks. Modern 'industrial metabolism' is fueled by energy-rich oil, coal, and natural gas and by nuclear, solar and hydroelectric power. Fuels and electricity are delivered by physical networks of pipe lines, power grids, roads, and railroads and by shipping and air traffic lanes. Recent work linking vascular networks and body size may underlie these similarities.

A theory for why metabolic rate scales sublinearly with body mass $(M)$, as approximately $M^{3 / 4}$ rather than linearly as $M^{1}$, is based on the observation that larger bodies have larger networks that can deliver resources at a faster rate but not in direct proportion to their larger size. As more branches are added to a network, the network transports materials over greater distances, taking more time and requiring progressively more infrastructure. Therefore, the rate of supply of resources to cells does not keep pace, so the mass-specific metabolic rate must decrease with increasing body size (West et al., 1997; Banavar et al., 2010). This theory illustrates two key features of biological energetics: (i) diminishing returns, so that a large organism uses proportionately less energy than a small one; and (ii) economies of scale, so that a large organism requires a lower rate of energy supply per unit mass than a small organism.

We hypothesize that industrial networks are similar to biological networks in two respects. First, modern industrial networks exhibit diminishing returns in that the investment in infrastructure must increase faster than the energetic return on those investments. Second, per capita industrial metabolism both drives and constrains many activities in modern human societies, including the activities of the individual people that consume resources from these networks (Moses, 2009).

Diminishing returns are evident in the scaling of U.S. urban road networks (Samaniego \& Moses, 2008). The per capita distance driven in U.S. metropolitan statistical areas (MSAs) increases with city size, but it increases less than expected for two reasons. First, population density tends to increase with metro area. Packing more people into a smaller area is an economy of scale that does not occur in organisms, where cell density does not change with body size. Second, unlike a vascular network where all blood flows out from a heart, much urban transport is decentralized - commuting to a local grocery store or gasoline station does not require driving through the city centre. To varying degrees, 'city morphology is reflected in a hierarchy of different subcenters or clusters across many scales, from the entire city to neighborhoods, organized around key economic functions' (Batty, 2008, p. 770).

Another economy of scale is evident in the relationship between per capita energy use and per capita gross domestic

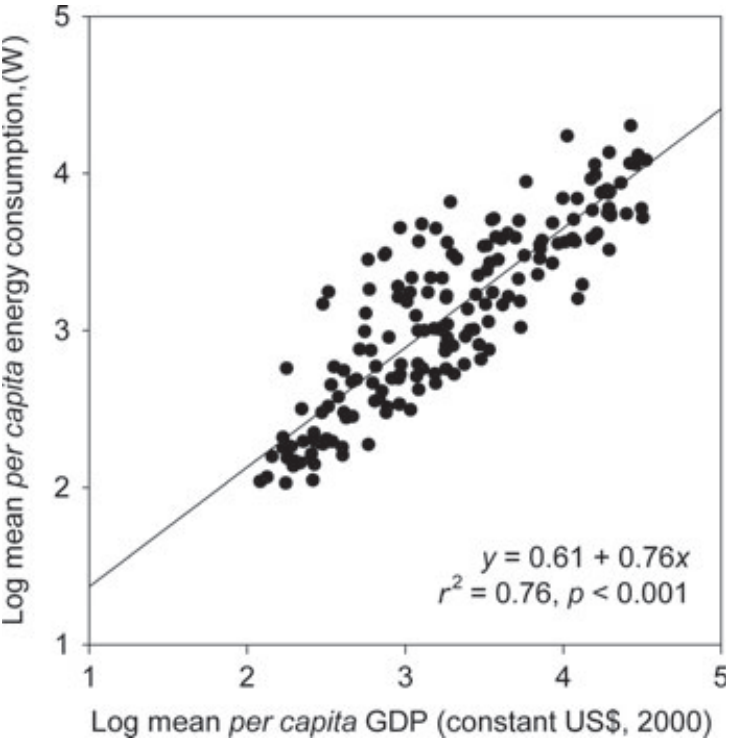

Fig. 9. A plot, on logarithmic axes, of per capita energy consumption as a function of per capita gross domestic product (GDP). The energy used to support an average individual's economy scales sublinearly with GDP, with an exponent of 0.76 using ordinary least squares (OLS) regression (95\% CI 0.69 - 0.82) (data from World Resources Institute, 2009, for the years 1980 to 2003). Total per capita energy consumption is calculated as the biological metabolism of individuals plus the energy derived from all other sources, including fossil fuels and renewables. Both sources of energy consumption were standardized by converting into W.

product (GDP) across nations. GDP is the total value of all goods and services exchanged in one year, in this case expressed in terms of \$US per capita. As shown in Fig. 9, this relationship is sublinear with an exponent close to $3 / 4$, uncannily similar to the scaling of metabolic rate. As national economies grow and consume more energy, less energy is required to generate each additional dollar of economic activity.

The relationship between individual energy use and societal economic growth exemplifies the difficulty of distinguishing economies of scale from decreasing returns. Consider the effect of switching the axes of Fig. 9. The figure makes the point that proportionately less energy is needed to fuel rising economic growth, but if the axes were reversed it would make the point that proportionately more money must be spent to produce each additional unit of energy. Clearly there are feedbacks between energy consumption and economic activity - over time, proportionately more money must be spent to extract resources (diminishing returns), but extracting resources generates proportionately more economic activity (increasing returns).

The trend of decreasing rates of increase of individual energy use with economic growth recalls similar patterns we have seen, including the economy of scale seen in the metabolism of organisms, where less energy is used per cell as body size increases. Tellingly, the scaling of energy use and economic activity in contemporary industrialized 
societies also recalls the economy of scale in space use with increasing population size in hunter-gatherer societies. The industrial networks that distribute energy, materials, and information are effectively modern extensions of traditional social networks, enabling people to extract and transport astronomically more resources and live at much higher population densities but at the cost of a slower life history and lower reproductive rate.

\section{URBAN SYSTEMS: GONGENTRATING PEOPLE, ENERGY, AND INNOVATION}

Throughout most of human history, societies were small and social relationships were based largely on kinship networks. With the transition to modern industrial societies, new networks for distributing energy, materials, and information accentuated some existing patterns while altering the socioeconomic basis of human existence. The human population, resource use, and technological and economic development have exploded on a staggering scale. What put humans on this path of ever-increasing exponential population and economic growth?

During the Paleolithic, rising population densities and attendant economic stresses promoted and accelerated cultural and technological evolution (Stiner et al., 1999; Kuhn \& Stiner, 1998). Similar dynamics are now at play at an unprecedented pace. Driving this pattern is the close connection between larger human populations, concentration of people in cities, and an increasing pace of innovation, which gives access to more natural resources and fuels the positive feedbacks (Bettencourt et al., $2007 a$; Bettencourt, Lobo \& West, 2009).

A

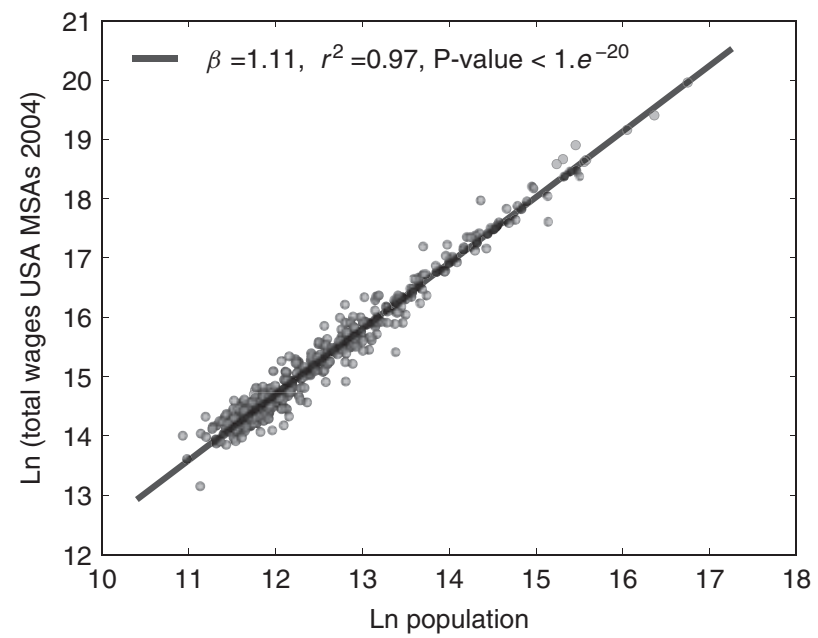

Cities highlight three conflicting trends driving human demands on ecological systems (Bettencourt et al., 2007a). First, cities concentrate people in smaller land areas, allowing economies of scale in infrastructure and social services. For example, the use of gas and electricity scales sublinearly with population size. As these efficiencies of scale are exploited, urban populations have a smaller ecological footprint per capita, in terms of space and resource use within a city, than the same population at a lower density. Second, urbanization spurs increased innovation, wealth creation, and attendant resource consumption (Romer, 1986; Krugman, 1991). As shown in Fig. 10, average income rises superlinearly, so that a doubling of urban population size raises the average income of residents by 10-20\% (Bettencourt et al., 2007a; Bettencourt, Lobo \& Strumsky, 2007b). The number of people in 'supercreative' jobs also grows superlinearly, as artists, entrepreneurs, companies, and universities spur innovation. Given the economic calculus of urban life, it is not surprising that cities emerged in similar form time and again in human history (Krugman, 1991). Third and on the flip side, social ills such as incidences of violent crime and infectious disease also increase superlinearly with population density.

These social changes accompany the demographic transition characteristic of economic development, the decrease in birth and death rates that follows rising wealth and cost of living. This change in life history is seen most notably in cities (Mace, 2008). Thus, urbanization affects the balance between the biological and human facets of our dual nature, enhancing sociocultural prerogatives while affecting basic metabolic and life-history parameters.

Two remarkable and universal features of human societies follow from these macroecological relationships. First, because socioeconomic quantities are rates (e.g. wages earned/person/year), their relative increase accelerates the

B

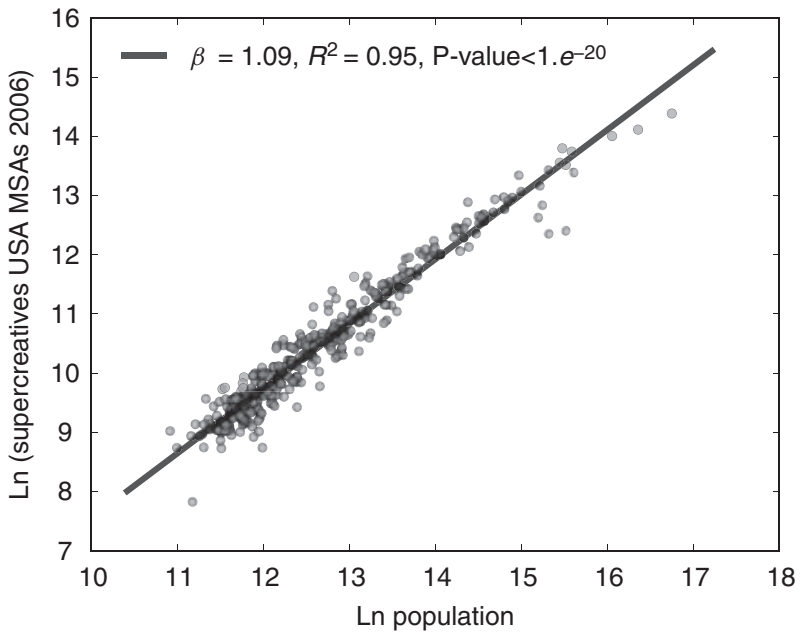

Fig. 10. Examples of superlinear scaling relationships in urban systems. (A) Relationship between wages and population size in U.S. metropolitan statistical areas (MSAs), regions formally designated as cities by the U.S. government. (B) The number of people employed in 'supercreative' jobs, such as artists, architects, scientists, and engineers, versus population size within MSAs. Data are plotted on logarithmic axes and exponents, $\beta$, and $r^{2}$ values from best-fit scaling relationships are shown (after Bettencourt et al., 2007a). 
pace of society (Bettencourt et al., 2007a). As a city grows, wealth creation, innovation, and other rhythms of social behaviour rise ever faster. Even the average pace that people walk increases with urban population. In essence, cities act as social accelerators. Second, because the relationships are self-similar, there are no characteristic scales at which they change qualitatively. Instead, the phenomena are power-law functions of city population size, rising superlinearly as long as urban populations grow.

There are no theoretical limits to such increasing returns with urban population size (Romer, 1986; Bettencourt et al., $2007 a$ ). Ecologists are familiar with growth curves that follow logistic shapes, reaching an asymptote at some environmental carrying capacity that constrains future population growth. However, human societies, and cities in particular, have repeatedly evaded resource constraints through continual innovation (Mumford, 1961). So long as the increasing returns feed back to sustain larger urban populations, then population growth will accelerate indefinitely as population size increases.

In reality, external perturbations or internal disruptions tend periodically to slow growth, resulting in punctuated, ever-shorter cycles (see Turchin, 2003). If a population grows faster than it can innovate or adapt to environmental change, then it can quickly collapse. Indeed, historians and archaeologists have documented multiple catastrophic declines and disappearances of cities and even entire societies (e.g. Mumford, 1961; Tainter, 1988; Diamond, 2005). So there are exceptions to the pattern of accelerating growth, often due to limitations of food and water supply or to outbreaks of violence and disease. Study of these cases will suggest when and why the pace of innovation was unable to keep up with the pace of growth and demand. Ultimately, it is important to reconcile this theoretical point with another, seemingly contradictory one: that it is impossible to sustain exponential growth trajectories indefinitely in a world of finite resources.

Given the Earth's finite resources and the tendency for feedbacks to increase the frequency of cyclical crises, population growth fueled by increasing returns is never stable. If the dominant mechanisms of human innovation and resource appropriation are the result of increasing returns to scale, then growth depends on continual and ever-faster adaptation. Given this caveat, what is the role of urbanization in the ecology of contemporary societies? Can the continued growth of cities contribute to rising living standards while decreasing the burden of human demands on the biosphere?

An optimistic scenario for the future of humanity offsets the seemingly unavoidable forces of urbanization with the attendant drop in fertility. Some of the most developed nations in Europe and Asia have stabilized population growth. However, they continue to urbanize, realizing increasing returns in wealth creation and innovation while exploiting economies in infrastructure and social services. Added to these advantages are opportunities to return formerly occupied land to natural habitat and to develop new technologies that may shrink per capita ecological footprints. A pessimistic scenario would take note that economic and population growth has been fueled by increased rates of per capita energy use (see above and Fig. 9). So far, this energy has come predominantly from fossil fuels, which are finite and being depleted rapidly. Unless the pace of innovation can supply energy at rates required to meet the demand for continued growth, current trajectories are unsustainable.

\section{GONGLUSIONS}

(1) The dual nature of $H$. sapiens is probably why most ecologists have shied away from studying our own species. Human ecology is subject to the same laws of nature that govern all living things. Human ecology is also affected by the uniquely human attributes that are the subjects of anthropology, sociology, economics, geography, and public health. Most scientists like to remain within the comfortable confines of their own discipline. Delving into human ecology means crossing the boundaries between the natural sciences and the social sciences.

(2) We have tried to show how studying relationships between humans and their environments through the lens of macroecology can lead to new insights and ways of thinking. Macroecological studies use large databases and statistical methods to integrate and synthesize across large scales of space and time. Applied to humans this means studying humans as they spread out of Africa to colonize the entire world, and as they transitioned from traditional hunter-gathers harvesting local resources to maintain subsistence economies to modern industrialtechnological societies harvesting fossil fuels and other resources on a global scale in an effort to sustain exponentially growing populations, cities, and economies.

(3) We define human macroecology as the study of humanenvironment interactions across spatial and temporal scales, linking small-scale interactions with large-scale, emergent patterns and their underlying processes.

(4) Macroecology has much to say about what it means to be human and about the present status and future prospects for humanity. Many of the ways that humans appear unique, as in our energetic, life-history, and cultural diversity patterns, are more matters of degree than kind and are often reflected in extensions of macroecological patterns common to other species. Others, such as the range of economies themselves, are uniquely human. Placing the scale and variation of human ecology in a grounded, mechanistic framework, one that can look across the range of human ecologies, is what differentiates this approach and what enables it to consider our dual nature in a powerfully unified manner.

\section{ACKNOWLEDGEMENTS}

The authors thank Jordan Okie, Wenyun Zuo, John de Long, Paul Hooper, Kenneth Letendre, Felisa Smith, Jeff Nekola, William Dunn, and students of the Perspectives in Human Ecology course at the University of New Mexico Biology Department 
for thoughtful discussions and helpful ideas. They also thank Katherine Smith, Jean-Francois Guegan, and J. Richard Stepp for permission to reproduce figures and an anonymous reviewer for helpful questions and suggestions.

\section{REFERENGES}

Allen, A. P., Brown, J. H. \& Gillooly, J. F. (2002). Global biodiversity, biochemical kinetics, and the energetic-equivalence rule. Science 297, 1545-48.

ANDERson, R. M. \& MAY, R. M. (1991). Infectious diseases of humans. Dynamics and control. Oxford University Press, Oxford.

Banavar, J. R., Moses, M. E., Brown, J. H., Damuth, J., Rinaldo, A., Sibly, R. M. \& Maritan, A. (2010). A general basis for quarter-power scaling in animals. Proceedings of the National Academy of Sciences 107, 15816-20.

Barrett, R., Kuzawa, C. W., McDade, T. W. \& Armelagos, G. J. (1998). Emerging and re-emerging infectious diseases: the third epidemiologic transition. Annual Review of Anthropology 27, 247-271.

Barthlott, W., Lauer, W. \& Placke, A. (1996). Global distribution of species diversity in vascular plants: Towards a world map of phytodiversity. Erdkunde 50, $317-328$.

Batty, M. (2008). The size, scale, and shape of cities. Science 319, 769-771.

BERLIN, B. (1992). Ethnobiological classification: Principles of categorization of plants and animals in traditional societies. Princeton University Press, Princeton.

Bettencourt, L. M. A., Lobo, J., Helbing, D., Kuehnert, C. \& West, G. B. (2007a). Growth, innovation, scaling, and the pace of life in cities. Proceedings of the National Academy of Sciences 104, 7301-7306.

Bettencourt, L. M. A., Lobo, J. \& Strumsky, D. (2007b). Innovation in the city: Increasing returns in patenting as a scaling function of metropolitan size. Research Policy 36, 107-120.

Bettencourt, L. M. A., Lobo, J. \& West, G. B. (2009). The self similarity of human social organization in cities. In Complexity perspectives on innovation and social change (eds D. Lane, D. Pumain, S. Van der Leeuw and G. West), pp. 221-236. Springer, Netherlands.

Binford, L. R. (2001). Constructing frames of reference. University of California Press, Berkeley.

Brown, J. H. (1995). Macroecology. University of Chicago Press, Chicago.

Brown, J. H., Gupta, V. K., Li, B-L., Milne, B. T., Restropo, C. \& West, G. B. (2002). The fractal nature of nature: Power laws, ecological complexity and biodiversity. Philosophical Transactions: Biological Sciences 357, 619-626.

Brown, J. H., Gillooly, J. F., Allen, A. P., Savage, V. M. \& West, G. B. (2004). Toward a metabolic theory of ecology. Ecology 85, 1771-1789.

CASE, T. J. (1978). On the evolution and adaptive significance of postnatal growth rates in the terrestrial vertebrates. Quarterly Review of Biology 53, 243-282.

CASHDAN, E. (2001). Ethnic diversity and its environmental determinants: Effect of climate, pathogens, and habitat diversity. American Anthropologist 103, 968-991.

Charnov, E. L. (1991). Evolution of life history variation among female mammals. Proceedings of the National Academy of Sciences 88, 1134-1137.

Charnov, E. L. \& Berrigan, D. (1993). Why do female primates have such long lifespans and so few babies? or Life in the slow lane. Evolutionary Anthropology $\mathbf{1}$ 191-194.

Collard, I. F. \& Foley, I. A. (2002). Latitudinal patterns and environmental determinants of recent human cultural diversity: do humans follow biogeographic rules? Evolutionary Ecology Research 4, 371-383.

Diamond, J. (2005). Collapse: How societies choose to fail or succeed. Penguin Books, London.

Dunn, R. R., Davies, T. J., Harris, N. G. \& Gavin, M. C. (2010). Global drivers of human pathogen richness and prevalence. Proceedings of the Royal Society B 277, $2587-2595$.

Field, R., Hawkins, B. A., Cornell, H. V., Currie, D. J., Diniz-Filho, J. A. F., Guégan, J.-F., Kaufman, D. M., Kerr, J. T., Mittelbach, G. G., Oberdor, T., O'Brien, E. \& Turner, J. R. G. (2008). Spatial species-richness gradients across scales: a meta-analysis. Fournal of Biogeography, doi: 10.1111/j.1365-2699.2008. 01963.x.

Fincher, C. \& Thornhill, R. (2008). A parasite-driven wedge: Infectious disease intensity may explain language and other biological diversity. Oikos 117, 1289-1297.

Fincher, C., Thornhill, R., Murray, D. R. \& Schaller, M. (2008). Pathogen prevalence predicts human cross-cultural variability in individualism/collectivism. Proceedings of the Royal Society B 275, 1279-1285.

Gaston, K. J. \& Blackburn, T. M. (2000). Pattern and process in macroecology. Blackwell Science, Oxford.

Grenfelt, B. T. \& Bolker, B. M. (1998). Cities and villages: infection hierarchies in a measles metapopulation. Ecology Letters 1, 63-70.

GrENFELL, B. T. \& Dobson, A. P. (1995). Ecology of infectious diseases in natural populations. Cambridge University Press, Cambridge.
Grimes, B. F. (ed.) (2000). Ethnologue, volume 1: Languages of the world, 14th ed. SIL International, Dallas.

Guernier, V. \& Guégan, J. F. (2009). May Rapoport's rule apply to human associated pathogens? EcoHealth 6, 509-521.

Guernier, V., Hochberg, M. E. \& Guégan, J. F. (2004). Ecology drives the worldwide distribution of human diseases. PLoS Biology 2, 740-746.

Gurven, M. (2004). To give and to give not: The behavioral ecology of human food transfers. Behavioral \& Brain Sciences 27, 543-583.

GuRven, M. \& Walker, R. S. (2006). Energetic demand of multiple dependents and the evolution of slow human growth. Proceedings of the Royal Society B 273, 835-841.

Hamilton, M. J., Burger, O., Delong, J., Walker, R. S., Moses, M. \& Brown, J. H. (2009). Population stability, cooperation and the invasibility of the human species. Proceedings of the National Academy of Sciences 106, 12255-12260.

Hamilton, M. J., Milne, B. T., Walker, R. S. \& Brown, J. H. (2007a). Nonlinear scaling of space use in human hunter-gatherers. Proceedings of the National Academy of Sciences 104, 4765-4769.

Hamilton, M. J., Milne, B. T., Walker, R. S., Burger, O. \& Brown, J. H. (2007b). The complex structure of hunter-gatherer social networks. Proceedings of the Royal Society B 274, 2195-2202.

Hawkes, K. \& Paine, R., (eds). (2006). The evolution of human life history. School of American Research Press, Santa Fe.

Hawkins, B. A., Field, R., Cornell, H. V., Currie, D. J., Guégan, J.-F., Kaufman, D. M., Kerr, J. T., Mittelbach, G. G., Oberdorff, T., O’Brien, E. M., Porter, E. E. \& Turner, J. R. G. (2003a). Energy, water, and broadscale geographic patterns of species richness. Ecology 84, 3105-3117.

Hill, K., Boesch, G., Goodall, J., Pusey, A., Williams, J. \& Wrangham, R. (2001). Mortality rates among wild chimpanzees. Fournal of Human Evolution 40, $437-450$.

Hill, R. A., Bentley, R. A. \& Dunbar, R. I. M. (2008). Network scaling reveals consistent fractal pattern in hierarchical mammalian societies. Biology Letters $\mathbf{4}$, $748-751$.

Hrdy, S. (2006). Evolutionary context of human development: The cooperative breeding model. In Attachment and bonding: A new synthesis (eds C. S. CARTER, L. Ahnert, K. Grossmann, S. Hrdy, M. Lamb, S. Porges, and N. Sachser). pp. 9-32. Dahlem Workshop Series of the Max Planck Institute, MIT Press, Cambridge, Massachusetts.

Jablonski, D., Roy, K. \& Valentine, J. W. (2006). Out of the tropics: Evolutionary dynamics of the latitudinal diversity gradient. Science $314,102-106$.

Jennings, S. \& Reynolds, J. D. (2007). Body size, exploitation and conservation of marine organisms. In Body size: The structure and function of aquatic ecosystems (eds A. G. Hildrew, D. G. Raffaeldi, and R. Edmonds-Brown), pp. 266-285. Cambridge University Press, Cambridge.

Jones, K. E., Patel, N. G., Levy, M. A., Storeygard, A., Balk, D., Gittleman, J. L. \& DASZAK, P. (2008). Global trends in emerging infectious diseases. Nature 451, 990-993.

Kaplan, H., Hill, K., Lancaster, J. \& Hurtado, A. M. (2000). A theory of human life history evolution: Diet, intelligence, and longevity. Evolutionary Anthropology $\mathbf{9}$, $156-185$.

Kaplan, H. S. \& Robson, A. J. (2002). The emergence of humans: The coevolution of intelligence and longevity with intergenerational transfers. Proceedings of the National Academy of Sciences 99, 10221-10226.

KELLY, R. L. (1995). The foraging spectrum: Diversity in hunter-gatherer liferways. Smithsonian Institution Press, Washington, D.C.

Kerr, J. T., Kharouba, H. M. \& Currie, D. J. (2007). The macroecological contribution to global change solutions. Science 316, 1581-1584.

Krugman, P. (1991). Increasing returns and economic geography. Fournal of Political Economy 99, 483-499.

Kunn, S. L. \& STiner, M. C. (1998). Middle Paleolithic 'creativity': Reflections on an oxymoron. In Creativity in human evolution and prehistory (ed. S. MITHEN), pp. 143-164. Routledge, London.

LAFFERTY, K. D. (2009). The ecology of climate change and infectious diseases. Ecology 90, 888-900.

Letendre, K., Fincher, C. L. \& Thornhill, R. (2010). Does infectious disease cause global variation in the frequency of intrastate armed conflict and civil war? Biological Reviezes 85, 669-683.

LiNo, M. (2010). Expenditures on children by families, 2009. U.S. Department of Agriculture, Center for Nutrition Policy and Promotion. Miscellaneous Publication No. 15282009.

Lyons, S. K., Smith, F. A. \& Brown, J. H. (2004). Of mice, mastodons and men: Human-mediated extinctions on four continents. Evolutionary Ecology Research 6, 339-358.

MACE, R. (2008). Reproducing in cities. Science 319, 764-766.

MACE, R. \& PAGEL, M. (1995). A latitudinal gradient in the density of human languages in North America. Proceedings of the Royal Society B 261, 117-121.

MAFri, L. (2005). Linguistic, cultural, and biological diversity. Annual Review of Anthropology 34, 599-617.

MARLOWE, F. W. (2001). Male contribution to diet and female reproductive success among foragers. Current Anthropology 42, 755-760. 
McMichael, A. J. (2004). Environmental and social influences on emerging infectious diseases: Past, present and future. Philosophical Transactions of the Royal Society B 359, $1049-1058$.

McNab, B. K. (1963). Bioenergetics and the determination of home range size. American Naturalist 97, 133-140.

Mittelbach, G. G., Schemske, D. W., Cornell, H. V., Allen, A. P., Brown, J. M., Bush, M. B., Harrison, S. P., Hurlburt, A. H., Knowlton, N., Lessios, H. A., McCain, C. M., McCune, A. R., McDade, L. A., McPeek, M. A., Near, T. J., Price, T. D., Ricklefs, R. E., Roy, K., Sax, D. F., Schluter, D., Sobel, J. M. \& Turelli, M. (2007). Evolution and the latitudinal diversity gradient: speciation, extinction and biogeography. Ecology Letters 10, 315-331.

Moore, J. L., Manne, T. M., Brooks, N., Burgess, R. \& Davis, L. A. (2002). The distribution of cultural and biological diversity in Africa. Proceedings of the Royal Society B 269, 1645-1653.

Moses, M. E. (2009). Being human: Engineering: Worldwide ebb. Nature 457, $660-661$

Moses, M. E. \& Brown, J. H. (2003). Allometry of human fertility and energy use. Ecology Letters 6, 295-300.

MumFord, L. (1961). The city in history: Its origins, its transformation, and its prospects. Harcourt Brace, New York.

Murdoch, G. P. (1967). Ethnographic atlas. University of Pittsburgh Press, Pittsburgh.

NetTLE, D. (1998). Explaining global patterns of language diversity. Fournal of Anthropological Archaeology 17, 354-374.

Nunn, C. L., Altizer, S. M., Sechrest, W. \& Cunningham, A. (2005). Latitudinal gradients of parasite species richness in primates. Diversity \& Distributions 11, 249-256.

Pascual, M. \& Bouma, M. J. (2009). Do rising temperatures matter? Ecology 90, 906-912.

Peters, R. H. (1983). The ecological implications of body size. Cambridge University Press, Cambridge.

Purvis, A., Webster, A. J., Agapow, P. M., Jones, K. E. \& IsaAc, N. J. B. (2003). Primate life histories and phylogeny. In Primate life histories and socioecology (eds P. M. Kappeler and M. E. Pereira), pp. 25-40. Cambridge University Press, Cambridge.

Roff, D. A. (2002). Life history evolution. Sinauer Associates, Sunderland.

RoHDE, K. (1992). Latitudinal gradients in species diversity: The search for the primary cause. Oikos 65, 514-527.

Romer, P. (1986). Increasing returns and long run growth. Fournal of Political Economy 94, $1002-1037$.

Samaniego, H. \& Moses, M. E. (2008). Cities as organisms: Allometric scaling of urban road networks in the USA. Fournal of Transport \& Land Use 1, 21-39.

SAx, D. (2001). Latitudinal gradients and geographic ranges of exotic species: implications for biogeography. Fournal of Biogeography 28, 139-150.

Sмiтн, E. A. (2001). On the coevolution of cultural, linguistic, and biological diversity. In On biocultural diversity: Linking language, knowledge, and the environment (ed. L. MAFFI). pp. 95-117. Smithsonian Institution Press, Washington, DC.
Smith, K. F., Sax, D. F., Gaines, S. D., Guernier, V. \& Guégan, J-F. (2007) Globalization of human infectious disease. Ecology 88, 1903-1910.

Stepp, J. R., Castaneda, H. \& Cervone, S. (2005). Mountains and biocultural diversity. Mountain Research and Development 25, 223-227.

Stepp, J. R., Cervone, S., Castaneda, H., Lasseter, A., Stocks, G. \& Gichon, Y. (2004). Development of a GIS for global biocultural diversity. Policy Matters 13 , $267-271$.

Steward, J. H. (1938). Basin-plateau aboriginal sociopolitical groups. United States Government Printing Office, Washington, DC.

Stiner, M. C., Munro, N. D., Surovell, T. A., Tchernov, E. \& Bar-Yosef, O. (1999). Paleolithic population growth pulses evidenced by small animal exploitation. Science 283, 190-194.

Sutherland, W.J. (1996). From individual behaviour to population ecology. Oxford University Press, Oxford.

SutherLand, W. J. (2003). Parallel extinction risk and global distribution of languages and species. Nature 423, 276-279.

Tainter, J. (1988). The collapse of complex societies. Cambridge University Press, Cambridge.

Tindale, N. (1974). Aboriginal tribes of Australia: Their terrain, environmental controls, distribution, limits, and proper names. University of California Press, Berkeley.

Turchin, P. (2003). Historical dynamics: Why states rise and fall. Princeton University Press, Princeton.

Viboud, G., Bjørnstad, O. N., Smith, D. L., Simonsen, L., Milleer, M. A. \& GrenfELl, B. T. (2006). Synchrony, waves, and spatial hierarchies in the spread of influenza. Science 312, 447-451.

Walker, R. M., Gurven, M., Hill, K., Migliano, A., Chagnon, N., De Souza, R., Djurovic, G., Hames, R., Hurtado, A. M., Kaplan, H., Kramer, K., Oliver, W. J., Valeggia, C. \& Yamauchi, T. (2006). Growth rates and life histories in twenty-two small-scale societies. American fournal of Human Biology 18, 295-311.

Watts, D., Muhamad, R., Medina, D. C. \& Dodds, P. S. (2005). Multiscale, resurgent epidemics in a hierarchical metapopulation model. Proceedings of the National Academy of Sciences 102, 11157-11162.

West, G. B., Brown, J. H. \& Enquist, B. J. (1997). A general model for the origin of allometric scaling laws in biology. Science 276, 122-126.

Wilcox, B. A. \& Gubler, D. J. (2005). Disease ecology and the global emergence of zoonotic pathogens. Environmental Health \& Preventive Medicine 10, 263-272.

Winterhalder, B. (1996). Social foraging and the behavioral ecology of intragroup resource transfers. Evolutionary Anthropology 5, 46-57.

Winterhalder, B. \& Smith, E. A. (2000). Analyzing adaptive strategies: Human behavioral ecology at twenty-five. Evolutionary Anthropology 9, 51-72.

Wolfe, N. D., Dunavan, C. P. \& Diamond, J. (2007). Origins of major human infectious diseases. Nature 447, 279-283.

WORLD RESOURCES INSTITUTE (2009). Earthtrends environmental information. URL http://earthtrends.wri.org/

(Received 24 January 2010; revised 21 June 2011; accepted 23 June 2011; published online 21 July 2011) 